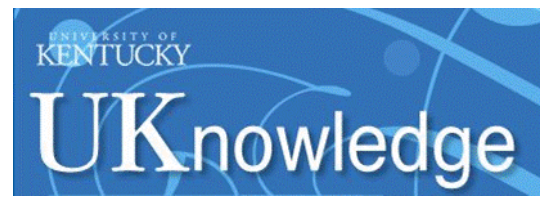

University of Kentucky

UKnowledge

Biosystems and Agricultural Engineering Faculty Publications

\title{
Phanerochaete chrysosporium Pretreatment of Biomass to Enhance Solvent Production in Subsequent Bacterial Solid- Substrate Cultivation
}

Wanying Yao

University of Kentucky

Sue E. Nokes

University of Kentucky, sue.nokes@uky.edu

Follow this and additional works at: https://uknowledge.uky.edu/bae_facpub

Part of the Bacteria Commons, Bioresource and Agricultural Engineering Commons, and the Oil, Gas, and Energy Commons

Right click to open a feedback form in a new tab to let us know how this document benefits you.

\section{Repository Citation}

Yao, Wanying and Nokes, Sue E., "Phanerochaete chrysosporium Pretreatment of Biomass to Enhance Solvent Production in Subsequent Bacterial Solid-Substrate Cultivation" (2014). Biosystems and Agricultural Engineering Faculty Publications. 167.

https://uknowledge.uky.edu/bae_facpub/167

This Article is brought to you for free and open access by the Biosystems and Agricultural Engineering at UKnowledge. It has been accepted for inclusion in Biosystems and Agricultural Engineering Faculty Publications by an authorized administrator of UKnowledge. For more information, please contact UKnowledge@lsv.uky.edu. 


\section{Phanerochaete chrysosporium Pretreatment of Biomass to Enhance Solvent Production in Subsequent Bacterial Solid-Substrate Cultivation}

Digital Object Identifier (DOI)

https://doi.org/10.1016/j.biombioe.2014.01.009

Notes/Citation Information

Published in Biomass and Bioenergy, v. 62, p. 100-107.

(c) 2014. This manuscript version is made available under the CC-BY-NC-ND 4.0 license https://creativecommons.org/licenses/by-nc-nd/4.0/.

The document available for download is the authors' post-peer-review final draft of the article. 


\section{Phanerochaete chrysosporium pretreatment of biomass to 2 enhance solvent production in subsequent bacterial solid- 3 substrate cultivation}

4

5 Wanying $\mathrm{Yao}^{1}$, Sue E Nokes ${ }^{1 *}$

$6 \quad{ }^{1}$ Department of Biosystems and Agricultural Engineering, University of Kentucky

7 C.E. Barnhart Building, Lexington, KY, 40546

8

9 Phone: 859.257 .3000 ext.128

10 Fax: 859.257.5671

11 Email: sue.nokes@uky.edu

12

13

14

15

16

17 
27 Abstract: This study investigated pretreatment of corn stover using solid substrate cultivation 28 (SSC) of Phanerochaete chrysosporium (P. chrysosporium) to improve subsequent accessibility to cellulose. Thereafter, Clostridium thermocellum (C. thermocellum) was directly inoculated onto the pretreated biomass to accomplish hydrolysis, followed by solventogenesis by introducing Clostridium beijerinckii (C. beijerinckii).

An enzyme suite containing laccase, lignin peroxidase and manganese peroxidase activity was detected during the cultivation of $P$. chrysosporium on corn stover within $288 \mathrm{~h}$ at an initial moisture content $w_{\mathrm{H}_{2} \mathrm{O}}=80 \%$ (mass of water/total mass). Incubation factors, such as substrate moisture content and cultivation temperature affected the percent of lignin removal which ranged from $14.4 \%$ to $36.4 \%$ of the original lignin. Lignin removal increased as the cultivation of $P$. chrysosporium continued but was accompanied by increased cellulose loss. The 7-day fungal cultivation sufficiently delignified the corn stover for the subsequent processing. Approximately $25 \%$ of the original lignin was removed; however $18 \%$ of the initial cellulose was also removed with the lignin. The investigations of the effect of fungal pretreatment were extended to miscanthus, wheat straw and switch grass. The yield of reducing sugar produced by $C$.

42 thermocellum on pretreated biomass was doubled compared with non-pretreated biomass,

43 demonstrating that pretreatment resulted in a more accessible carbon source for the solvent-

44 producing bacterium. The final comprehensive comparison between the pretreated biomass and non-pretreated biomass on the three-stage SSC for butanol production showed pretreatment by $P$. chrysosporium improved microbial utilization of lignocellulosic materials for solvent production by approximate 4 - 7 folds.

Key words: P. chrysosporium, lignin removal, cellulose hydrolysis Clostridium thermocellum, 


\section{Introduction}

The global energy crisis has spurred interest in producing alternative biofuels from clean, renewable feedstocks via biological processes. Because of several desirable physical and chemical properties, butanol is currently a favored alternative to ethanol [1]. Butanol can be produced by an acetone, butanol and ethanol (ABE) fermentation via the anaerobic conversion of carbohydrates by Clostridium strains [2]. ABE fermentation was popular in the early $20^{\text {th }}$ century. However, the ABE process eventually suffered from the high cost of conventional starch (maize, wheat, millet, etc.) or sugar (molasses) substrates, and was abandoned in favor of chemical synthesis of these chemicals. Current interest in biofuel production has stimulated research into the use of less expensive substrates [3,4] for the ABE fermentation. Being the most abundant renewable resource, lignocellulose is recognized as a promising feedstock for use in biofuel fermentation, provided that the cellulose components can be deconstructed and utilized efficiently [5]. Since the ability of butanol-producing bacteria to catalyze the complex lignocellulosic feedstocks is limited, lignin removal or modification followed by cellulose hydrolysis is required to convert the lignocellulose into simpler sugars prior to the butanol fermentation. Chemical pretreatment combined with enzymatic saccharification of agricultural residues has been adopted as the conventional method to generate reducing sugars prior to solvent production [6-8]. However, inhibitors present after pretreatment and the high cost of hydrolytic enzymes have hindered process industrialization $[9,10]$. These concerns motivated this study to develop a mild pretreatment with cost-effective hydrolysis for the ABE

78 fermentation process.

Among the methods of pretreatment available, biological pretreatment with lignolytic enzymes is said to be superior to the current chemical and thermochemical methods in terms of energy intensity, environmental impact, and reduced production of chemicals toxic to fermentation microorganisms [11]. The enzymes commonly found in a lignolytic enzyme complex consist mainly of enzymes with lignin-degrading peroxidase activity (LiP; E.C.1.11.1.14), manganese peroxidase activity (MnP; E.C.1.11.1.13) and the lignin-degrading enzyme laccase activity (E.C.1.10.3.2). Some or all of these enzymes and their isozymes are produced by a number of

87 wood-rotting fungi $[12,13]$. The white-rot basidiomycete, Phanerochaete chrysosporium $(P$. 
chrysosporium) is reported to have high lignolytic activity. This strain is considered to be a model strain for the development and understanding of the lignolytic enzyme production system because it can produce a more complete lignolytic enzyme complex than most other strains [13, 14].

Following pretreatment, the cellulose hydrolysis step could be accomplished using commercial enzymes (predominately fungal enzymes), however an alternative approach was used in this study. The alternative approach involved cultivating the solvent-producing Clostridia with a microorganism that can enzymatically convert cellulose into reducing sugars. There have been several reports of co-cultivations [15-17] using a cellulolytic strain like Clostridium thermocellum (C. thermocellum), Clostridium cellulolyticum or Bacillus thermoamylovorans to produce cellulase for saccharification of lignocellulose or cellulose (rice straw with swine dung, cellulose or solka floc), followed by butanol production achieved by adding a solventogenic species such as Clostridium acetobutylicum or $C$. beijerinckii. These studies report that sequential co-culture increased the total fermentation products formed from cellulosic substrate by 1.7 to 2.6 -fold compared to $C$. beijerinckii monoculture.

The hypothesis for the current study was that a biological pretreatment followed by a sequential co-culture could efficiently utilize lignocellulosic substrate to produce solvents. To our knowledge, there are no previous studies investigating the effect of biological pretreatment on increasing substrate utilization and butanol yield, particularly for this co-culture process. Moreover, although sequential co-cultures have been investigated as a way of increasing the production of butanol using ideal feedstocks (pretreatment unnecessary), the studies were only performed in liquid fermentation. Solid substrate co-culture cultivation, which has been shown to have advantages over liquid cultivation [15] , has not been previously conducted using sequential co-cultures for $\mathrm{ABE}$ production.

To address this research gap, the objective of this study was to develop an appropriate biological pretreatment method which would increase the fermentability of lignocellulosic feedstocks intended for subsequent co-culture; specifically to increase cellulose accessibility and solvent accumulation in solid substrate cultivation. The fungal pretreatment of corn stover using SSC of 
P. chrysosporium was investigated as a method to improve accessibility to cellulose in the pretreatment stage by preferentially degrading the lignin. Thereafter, $C$. thermocellum was directly inoculated onto the pretreated biomass to accomplish hydrolysis, followed by solvent production initiated by introducing $C$. beijerinckii. The study investigated the effect of cultivation conditions (moisture content of initial substrate and culture temperature) on the lignin removal by $P$. chrysosporium and then investigated the effects of lignin degradation on the subsequent fermentability by a bacterial co-culture, quantified by availability of carbohydrates and solvent production. A comprehensive analysis between fungal pretreated and non-pretreated biomass (corn stover, miscanthus, switch grass and wheat straw) on metabolite accumulation was performed to evaluate the effect of pretreatment on the solid substrate co-culture fermentation.

\section{Materials and Methods}

\subsection{Strain cultivation}

The white-rot basidiomycete, $P$. chrysosporium strain (ATCC MYA-4764) was obtained from the American Type Culture Collection (ATCC, Rockville, MD ) and maintained as a frozen culture $\left(-80{ }^{\circ} \mathrm{C}\right)$ in $30 \%$ glycerol. Propagation of the organism for SSC was performed as described by Shi et al. [16]. Spore suspensions were prepared by washing the slant with $10 \mathrm{~cm}^{3}$ of sterilized sodium acetate buffer $\left(50 \mathrm{mmol} \mathrm{dm}^{-3}, \mathrm{pH} 4.5\right)$. The final spore inoculum concentration was $5 \times 10^{6}$ spores $\mathrm{cm}^{-3}$, determined using a hemocytometer.

C. thermocellum ATCC 27405 was obtained from ATCC and grown in basal medium that contained (per L) [17]: $1530 \mathrm{mg} \mathrm{Na} 2 \mathrm{HPO}_{4}, 1500 \mathrm{mg} \mathrm{KH}{ }_{2} \mathrm{PO}_{4}, 500 \mathrm{mg} \mathrm{NH} 4 \mathrm{Cl}, 500 \mathrm{mg}$ $\left(\mathrm{NH}_{4}\right)_{2} \mathrm{SO}_{4}, 90 \mathrm{mg} \mathrm{MgCl} \cdot 6 \mathrm{H}_{2} \mathrm{O}, 30 \mathrm{mg} \mathrm{CaCl}$, $4000 \mathrm{mg}$ yeast extract, $10 \mathrm{~cm}^{3}$ standard vitamins [18], $5 \mathrm{~cm}^{3}$ modified metals [18], $500 \mathrm{mg}$ cysteine hydrochloride, $1 \mathrm{~cm}^{3}$ resazurin, and $4000 \mathrm{mg}$ sodium carbonate. The medium $\mathrm{pH}$ was adjusted to 6.7 with $\mathrm{NaOH}$ and maintained under a $100 \%$ carbon dioxide atmosphere by sparging with $\mathrm{CO}_{2}$ followed by sealing the container. $C$. beijerinckii ATCC 51743 purchased from ATCC was used in this study. For seed culture preparation, stock cultures were heat-shocked at $80^{\circ} \mathrm{C}$ for $10 \mathrm{~min}$, and transferred anaerobically into Reinforced Clostridial medium (RCM, Difco Laboratories, Detroit, Mich.) at $35{ }^{\circ} \mathrm{C}$ for $24 \mathrm{~h}$. 


\subsection{Lignin analysis and biomass composition}

The four types of biomass (corn stover, miscanthus, switch grass and wheat straw) used in this study were collected by rotary disc mower at $10 \mathrm{~cm}$ above the ground from the University of Kentucky North Farm in 2011. Switch grass (Alamo) and miscanthus (miscanthus x giganteus) were from the geographical coordinates 38.132396,-84.495948. Geographical coordinates for the wheat straw collection area were 38.080392,-84.737899. Corn stover was collected from the geographical coordinates $36.801519,-86.769254$. Biomass samples consisted of the whole plant above ground (including stems and leaves), however grain had been previously removed from the corn stover and wheat straw. The biomass was stored in small square bales with $w_{\mathrm{H}_{2} \mathrm{O}}<15 \%$ for 9 months. The bales were ground to $5 \mathrm{~mm}$, thoroughly mixing the plant tissue. Samples were air-dried and stored at room temperature.

Biomass composition was determined using NREL methods [19]. Acid soluble lignin was measured using UV-vis spectrophotometry by quantifying absorption at $205 \mathrm{~nm}$. The corn stover used in this study initially contained $21.52 \%$ of total lignin (Table 1) which consisted of $19.26 \%$ acid insoluble and $2.25 \%$ of acid soluble lignin. The analysis of lignin degradation (LD) was conducted following Shi et al. [20] as shown Eq. (1)
$L D=1-\frac{\omega \cdot(\alpha+\beta)}{\omega_{0} \cdot\left(\alpha_{0}+\beta_{0}\right)} \times 100 \%$
Equation 1

Where $\omega$ is the dry weight of the treated sample $(\mathrm{g}) ; \omega_{0}$ is the initial dry weight of the untreated sample (g); $\alpha, \beta$ are the $\%$ of acid-soluble and acid-insoluble lignin respectively of the treated sample and $\alpha_{0}, \beta_{0}$ are the $\%$ of acid-soluble and acid-insoluble lignin of the untreated sample. 


\subsection{Solid-substrate culture (SSC)}

In SSC, the pretreatment of $0.5 \mathrm{~g}$ biomass by $P$. chrysosporium $\left(50 \mathrm{~mm}^{3}\right.$ of spore culture) was conducted in $18 \times 150 \mathrm{~mm}$ modified Hungate tubes at $35^{\circ} \mathrm{C}$ using cotton plugs in the tubes to allow for oxygen exchange with the environment. Prior to the inoculation of $C$. thermocellum, the tube with fungal pretreated biomass was flushed with $\mathrm{CO}_{2}$ for 20 minutes and then sealed with a rubber topper and an aluminum seal finish. $2.0 \mathrm{~cm}^{3}$ of standard inoculum of $C$. thermocellum was injected into the sealed test tube through the rubber stopper with a syringe. The $\mathrm{CO}_{2}$ along with the gas generated from $C$. thermocellum maintain the anaerobic condition for the mono and co-culture. After a 2-day cultivation of $C$. thermocellum at $65{ }^{\circ} \mathrm{C}$, an inoculum of $1 \mathrm{~cm}^{3} C$. beijerinckii at exponential phase per gram biomass was injected into the test tube through the rubber stopper. The co-culture was incubated at $35^{\circ} \mathrm{C}$ in the water bath for 2 days. Destructive sampling of SSC bottles involved addition of $10 \mathrm{~cm}^{3} 100 \mathrm{mmol} \mathrm{dm}$-3 potassium phosphate $(\mathrm{pH} 7)$ followed by centrifugation $(5000 \times g, 10 \mathrm{~min})$ of this mixture. The cell-free supernatant was stored at $-20{ }^{\circ} \mathrm{C}$ for further analysis.

\subsection{Measurement of enzyme activity from $P$. chrysosporium}

Lignin peroxidase (LiP) was assayed on the basis of increased absorbance at $370 \mathrm{~nm}$ reflecting the oxidation change of veratryl alcohol to veratraldehyde [21]. One unit of the enzyme activity (1U) of LiP was defined as the amount of enzyme required to produce $1 \mu \mathrm{mol}$ veratraldehyde per minute. The activity of MnP was determined by the increased absorbance at $240 \mathrm{~nm}$ corresponding to the oxidation change of $\mathrm{Mn}^{2+}$ to $\mathrm{Mn}^{3+}$ [22]. One unit of the enzyme activity of $\mathrm{MnP}$ was defined as 0.1 changes in absorbance per minute. The corresponding protocols can be found in Xu et al. [23]. The activity of laccase was determined by recording the increase of absorbance at $530 \mathrm{~nm}$ in a $3.00 \mathrm{~cm}^{3}$ reaction mix containing $73 \mathrm{mmol} \mathrm{dm}^{-3}$ potassium phosphate, $0.02 \mathrm{mM}$ syringaldazine, $10 \%$ methanol, and 12.5 to 25.0 units laccase [24].

\subsection{Analysis of co-culture's metabolite production}

Fermentation samples (see section 2.3) were centrifuged at 9,600 $\times \mathrm{g}$ and the products in the supernatants (lactic acid, acetic acid, butyric acid, ethanol, butanol and acetone) were quantified by high-performance liquid chromatography (HPLC) using a Dionex UltiMate 3000 system 
(Dionex Corporation, Sunnyvale, California). A 300x7.8mm Aminex 87H column was maintained at $20{ }^{\circ} \mathrm{C}$ with a micro-guard cationic $\mathrm{H}$ cartridge at room temperature. The eluent was $5 \mathrm{mmol} \mathrm{dm}{ }^{-3} \mathrm{H}_{2} \mathrm{SO}_{4}$ at a flow rate $0.4 \mathrm{~cm}^{3} \mathrm{~min}^{-1}$. The metabolites were detected using shodex 101 refractive index detector.

\subsection{Experimental Design and Data analysis}

Experiments were conducted in two stages. First, the optimal moisture content was determined. SSCs were incubated at $35{ }^{\circ} \mathrm{C}$ for 10 days at 4 levels of $w_{\mathrm{H}_{2} \mathrm{O}}=50,68,80,85 \%$. Next, the optimal moisture content was used to determine optimal culture temperature. SSCs were incubated for 10 days at $w_{\mathrm{H}_{2} \mathrm{O}}$ of $80 \%$ at 3 levels of temperatures $\left(25,30,35^{\circ} \mathrm{C}\right)$. All experiments were conducted in replicate and the data presented were mean values. ANOVA was employed with SPSS (Chicago, IL) to evaluate statistical differences between treatments. Statistical significance was defined as $\mathrm{p}<0.05$.

\section{Results and Discussion}

\subsection{Enzymes suite and growth of $P$. chrysosporium on corn stover using SSC}

Laccase, LiP and MnP activity was detected during the cultivation of P. chrysosporium $\left(w_{\mathrm{H}_{2} \mathrm{O}}=\right.$ $80 \%$ by 288 h. Laccase activity was detected earlier than the activity of the other two enzymes (LiP and MnP) and reached the maximum $\left(1.87 \mathrm{U} \mathrm{cm}^{-3}\right.$ or about $49 \mathrm{U} \mathrm{g}^{-1}$ dry mass) after $166 \mathrm{~h}$ of cultivation but declined to about $1.20 \mathrm{U} \mathrm{cm}^{-3}$ in the following $60 \mathrm{~h}$ of cultivation. Genomic sequence searches of $P$. chrysosporium MYA revealed no conventional laccase sequence but did detect several multicopper oxidase sequences [25]. The detected laccase activity in our study may be attributed to these multi-copper oxidases. Because the conventional laccase is also a multi-copper oxidase and these related non-conventional oxidases may perform the extracellular oxidations. $P$. chrysosporium is known to decompose lignin by excreting extra-cellular peroxidases ( $\mathrm{LiP}$ and $\mathrm{MnP}$ ) under nutrient starvation $[20,26]$. The production of $\mathrm{LiP}$ and $\mathrm{MnP}$ activity reached a maximum after $288 \mathrm{~h}$ at $0.248 \mathrm{U} \mathrm{cm}^{-3}\left(6.5 \mathrm{U} \mathrm{g}^{-1}\right.$ dry mass $)$ and $0.151 \mathrm{U} \mathrm{cm}^{-3}$ (4.0 $\mathrm{U} \mathrm{g}^{-1}$ dry mass), respectively. The activity of all three enzymes stabilized around 288 hours and remained constant for the remaining of the experiment. Previous studies report that nitrogen 
stimulated fungal growth and enzyme synthesis/activity for several white rot fungal strains in SmF [27, 28]. For SSC, Asgher [29] detected a maximum LiP activity of $7.26 \mathrm{U} \mathrm{g}^{-1}$ dry mass after 7 days SSC using corn cobs moistened with Kirk's basal medium. Further addition of yeast extract $0.2 \%$ or peptone $0.3 \%$ increased LiP activity to $11.27 \mathrm{U} \mathrm{g}^{-1}$ dry mass or to $12.26 \mathrm{U} \mathrm{g}^{-1}$ dry mass, respectively. In our study $P$. chrysosporium produced an enzyme suite of laccase, LiP and $\mathrm{MnP}$ activity with no nitrogen or carbon supplementation except what the fungus could extract from the corn stover substrate.

The composition and relative yields of the fungal enzyme activity have been reported to be strongly affected by the substrate type. Couto et al. [30] and Moldes et al. [31] reported the stimulating effect of lignin for laccase production by the white-rot fungus Trametes versicolor using lignocellulosic substrate. Gassara (2010) claimed that the high levels of insoluble carbohydrates, such as cellulose, hemicellulose, and lignin content of apple pomace stimulated high values of laccase and peroxidase (LiP and $\mathrm{MnP}$ ) synthesis/activity by P. chrysosporium. Our results differs from previous reports [32-34] in the relative composition of enzyme suite, which was expected because we used a different substrate. In addition, we saw a strong correlation between mycelial growth and peroxidase ( $\mathrm{LiP}$ and $\mathrm{MnP})$ activity. The timing of the initial measurement of LiP and MnP activity is consistent with the increase in fungal mycelia growth visually observed after 5 days culture (Figure 2).

Figure 2 presents the mycelial growth of $P$. chrysosporium during the 11-day SSC. SSC processes differ from SmF, since microbial growth initiates at the surface of the solid substrate particles while mycelial pellets are typically formed in $\mathrm{SmF}$ [35]. In the current study, the mycelia of $P$. chrysosporium initiated on the surface of the corn stover presumably because oxygen could be easily accessed. Accumulated mycelia were observable on the surface of the corn stover after 5 days. As the cultivation continued, the mycelia gradually penetrated deeper into the biomass and finally through the entire biomass after 11 days of culture. No substantial mycelial growth was observed after day 11. The conventional opinion states that the success of the SSC is directly related to the appropriate particle size of the support, which influences both nutrient diffusion and fungal cell attachment [36]. Generally, smaller substrate particles provide a larger surface area for microbial colonization but particles which are too small may result in poor growth due to substrate agglomeration which restricts nutrient and oxygen accessibility. In 
258 contrast, larger particles provide better aeration but a limited surface for microbial colonization

259 [37]. A particle size of $5 \mathrm{~mm}$ seemed to be an appropriate size to support microbial activity as 260 evidenced above.

\subsection{Effect of cultivation conditions on lignin removal of corn stover}

262

263

264

265

266

267

268

269

270

271

272

273

274

275

276

277

278

279

280

281

282

The percent of lignin removed is positively correlated with the water content of initial substrate as seen in Fig.3. Water in SSC functions as a solvent to transport nutrients as well as to help maintain stable cellular and molecular structures [20,38]. Although fungal growth can be initiated at $w_{\mathrm{H}_{2} \mathrm{O}}$ of $50 \%$, the metabolic functions of $P$. chrysosporium apparently cannot be actively supported, as evidenced by only $15 \%$ of the original lignin in corn stover removed. The $w_{\mathrm{H}_{2} \mathrm{O}}=80 \%$ and $w_{\mathrm{H}_{2} \mathrm{O}}=85 \%$ treatments demonstrated approximately $35 \%$ lignin degradation after 10 days. Our results demonstrated that moisture content affected fungal growth as well as the lignin degrading performance in SSC systems, which was also reported in As claimed by Lousane et al. [39] and Mitchell et al. [40]. These results were also consistent with the observation that $P$. chrysosporium in SSC requires moisture contents ranging between $40 \%$ and $90 \%$ [29]. Ironically, higher moisture contents limit oxygen transfer, often inhibiting aerobic SSC cultures, and increasing susceptibility to bacterial contamination [20, 29], however we did not see this effect in our cultures.

Cultivation temperature had a significant effect on lignin removal (Figure 4). Up to $35 \%$ acid insoluble lignin and $21 \%$ acid soluble lignin of the corn stover was removed when cultivated at $30{ }^{\circ} \mathrm{C}$ to $35^{\circ} \mathrm{C}$, which was significantly higher than the lignin removed at $25^{\circ} \mathrm{C}$ (approximately $15 \%$ ASL). No effects of temperature were observed for acid insoluble lignin removal. 


\subsection{Effect of fungal pretreatment on $C$. thermocellum growth and metabolites}

Ideally an effective fungal pretreatment would reduce the percentage of lignin in the original substrate while simultaneously conserving the cellulose polymers. In our study, a direct relationship between cellulose loss and lignin removal was observed in corn stover. An increase in lignin removal from $14.37 \%$ to $36.40 \%$ was accompanied by an increasing loss of cellulose from $11.78 \%$ to $28.75 \%$, likely because more cellulose was accessible to the fungus as its carbon source through decomposition of the lignin structure. An approximate cellulolytic activity of $0.1 \mathrm{U} \mathrm{cm}^{-3}$ (2.14 $\mathrm{U} \mathrm{g}^{-1}$ initial substrate) was detected in the washed broth of the 11th day SSC. The cellulase secreted by $P$. chrysosporium facilitated the enzymatic degradation of cellulose to sugars available for use by the fungi, which lowered the overall availability of carbohydrates for the subsequent fermentation. Others have observed cellulolytic activity in wood-rotting fungi [41]. Once total lignin content dropped below $14.2 \%$ of the total biomass composition, no additional improvement in metabolite accumulation by $C$. thermocellum was observed.

Ethanol was also produced during the fungal fermentation. The ethanol content ranged from 0.10 to $0.85 \mathrm{mg} \mathrm{g}^{-1}$ corn stover in treatments where the lignin removal was $14.4-36.4 \%$ of the total lignin respectively. Some researchers also claim that several species of white-rot fungi are capable of producing ethanol (0.17 - $0.42 \mathrm{~g} \mathrm{~g}^{-1}$ substrate) directly from cellulosic biomass [42, 43]. However, $P$. chrysosporium is not a major ethanol producer. The major role of $P$. chrysosporium utilized in this study was to delignify the biomass for subsequent processing steps, and ethanol was not the focus of our study.

Typically, ethanol and acetate are the main extracellular metabolites produced by C. thermocellum monocultures. In our study, increasing the percent lignin removal from $14.4 \%$ to $27.3 \%$ had a positive effect on glucose and cellobiose generated by $C$. thermocellum's enzyme system (but not total metabolites produced - see above) with the largest amount being $19.17 \mathrm{mg}$ glucose $\mathrm{g}^{-1}$ initial substrate and $18.12 \mathrm{mg}$ cellobiose $\mathrm{g}^{-1}$ initial substrate, respectively but lignin removal had a limited effect on acetate production. Further lignin removal from $27.3 \%$ to $36.4 \%$ did not increase metabolite (ethanol and acetate) accumulation however the cultures did consume more of the carbon source (glucose and cellobiose) ideally meant for the subsequent fermentation. This can be seen in Table 2, where an increase in lignin removal from $27.3 \%$ to 
$36.4 \%$ resulted in an increased loss of cellulose from $18.78 \%$ to $30.75 \%$. Our data inferred that the optimal pretreatment with 25 - $27 \%$ of lignin removed (7-day cultivation) saved more cellulose for the subsequent cultivation.

\subsection{Evaluation of $P$. chrysosporium pretreatment method on solid substrate batch sequential co-culture of $C$. thermocellum and $C$. beijerinckii on four types of biomass}

The yield of glucose produced by $C$. thermocellum on biomass pretreated with $P$. chrysosporium was at least twice that of non-pretreated biomass (Fig. 5) for all four types of biomass, corn stover, miscanthus, switchgrass. We hypothesize that lignin removal by $P$. chrysosporium exposed the cellulose to the bacterial enzyme systems, leading to the efficient access and utilization of cellulose resulting in more accessible carbon available for the solvent phase microorganism.

All treatments produced approximately the same amount of ethanol (Fig. 5). However, becasue the co-cultivation for solvent production is the ultimate goal of our project, significant metabolite production during the $C$. thermocellum phase was not a priority, and in fact was undersirable. Ideally the $C$. thermocellum step in the process would leave only carbohydrates for the sequential co-culture to use as feedstock for $C$. beijerinckii to produce acids and solvents. The acids produced by $C$. thermocellum should not exceed a critical point to avoid creating unfavorable osmotic conditions for $C$. beijerinckii, resulting in metabolic inhibition [17]. Thus it is essential to not only adopt an effective pretreatment method with little carbon loss or inhibitors produced but also control the metabolite production of $C$. thermocellum in order to direct the cultivation stage transition and sustain an appropriate environment for $C$. beijerinckii in the sequential coculture. In summary, the fungal pretreated biomass showed better performance than nonpretreated ones in terms of cellulose hydrolysis by $C$. thermocellum and in retaining carbon for C. beijerinckii. Significantly more butanol was produced from the fungal pretreated biomass as compared to non-pretreated biomass (Table 3) for all types of biomass investigated. The fungalpretreated miscanthus corresponded to the highest yield of butanol, being $3.66 \mathrm{mg} \mathrm{g}^{-1}$ biomass (equal to a titre of $0.6 \mathrm{~g} \mathrm{dm}^{-3}$ ). The study confirmed the positive effect on lignin removal by fungal pretreatment when using corn stover in a sequential co-culture ABE fermentation and extended the established three-stage SSC model to wheat straw, switch grass, and miscanthus. 
The study investigated the effect of solid substrate cultivation conditions on the lignin removal by $P$. chrysosporium, and the subsequent fermentability of the pretreated substrate by a bacterial co-culture. Up to $36.4 \%$ of total lignin was removed when cultivation of $P$. chrysosporium was maintained at $35^{\circ} \mathrm{C}$ and $w_{\mathrm{H} 2 \mathrm{O}}=80-85 \%$ but accompanied by the cellulose consumed as well. The optimal pretreatment resulted in a $25-27 \%$ of lignin removed (7-day cultivation of $P$. chrysosporium), which saved more cellulose for the sequential co-cultivation. $C$. thermocellum in SSC grown on fungal pretreated biomass degraded the substrate into a significantly higher amount of glucose than cultures grown on non-pretreated biomass. Significantly higher yields of butanol were generated by fermenting fungal pretreated biomass compared to the non-pretreated biomass. Those observations demonstrated the efficient conversion of lignocellulosic material after fungal pretreatment, which resulted in more value-added acids and solvents.

\section{Acknowledgement}

The authors sincerely acknowledge the financial support of the United States Department of Agriculture National Institute for Food and Agriculture Biomass Research and Development Initiative Grant \# 2011-10006-30363. The investigation reported in this paper (No. Xx-Xx-Xxx) is a part of a project of the Kentucky Agricultural Experiment Station and is published with the approval of the director. 
372

373

374

375

376

377

378

379

380

381

382

383

384

385

386

387

388

389

390

391

392

393

394

395

396

397

398

399

400

401

402

\section{References}

[1] Nigam PS, Singh A. Production of liquid biofuels from renewable resources. Prog Energy Combust Sci 2011;37(1):52-68.

[2] Clark JH, Luque R, Matharu AS. Green chemistry, biofuels, and biorefinery. Annual Review of Chemical and Biomolecular Engineering 2012;3:183-207.

[3] Lenz TG, Moreira AR. Economic-evaluation of the acetone-butanol fermentation. Abstracts of Papers of the American Chemical Society 1980;179(MAR):33-INDE. [4] Jones DT, Woods DR. Acetone-butanol fermentation revisited. Microbiol Rev 1986;50(4):484-524.

[5] Kumar P, Barrett DM, Delwiche MJ, Stroeve P. Methods for pretreatment of lignocellulosic biomass for efficient hydrolysis and biofuel production. Ind Eng Chem Res 2009;48(8):3713-29. [6] Qureshi N, Ezeji TC, Ebener J, Dien BS, Cotta MA, Blaschek HP. Butanol production by Clostridium beijerinckii. Part i: Use of acid and enzyme hydrolyzed corn fiber. Bioresour Technol 2008;99(13):5915-22.

[7] Soni BK, Das K, Ghose TK. Bioconversion of agro-waste into acetone butanol. Biotechnol Lett 1982;4(1):19-22.

[8] Thirmal C, Dahman Y. Comparisons of existing pretreatment, saccharification, and fermentation processes for butanol production from agricultural residues. Can J Chem Eng 2012;90(3):745-61.

[9] Qureshi N, Saha BC, Hector RE, Cotta MA. Removal of fermentation inhibitors from alkaline peroxide pretreated and enzymatically hydrolyzed wheat straw: Production of butanol from hydrolysate using Clostridium beijerinckii in batch reactors. Biomass Bioenerg 2008;32(12):1353-8.

[10] Ezeji T, Qureshi N, Blaschek HP. Butanol production from agricultural residues: Impact of degradation products on Clostridium beijerinckii growth and butanol fermentation. Biotechnol Bioeng 2007;97(6):1460-9.

[11] Ward OP, Singh A. Bioethanol technology: Developments and perspectives. Adv Appl Microbiol 2002;51:53-80.

[12] Rosenberg SL. Patterns of diffusibility of lignin and carbohydrate-degrading systems in wood-rotting fungi. Mycologia 1980;72(4):798-812. 
[13] Singh D, Chen SL. The white-rot fungus Phanerochaete chrysosporium: Conditions for the production of lignin-degrading enzymes. Appl Microbiol Biotechnol 2008;81(3):399-417. [14] Orth AB, Royse DJ, Tien M. Ubiquity of lignin-degrading peroxidases among various wood-degrading fungi. Appl Environ Microbiol 1993;59(12):4017-23. [15] Chinn MS, Nokes SE, Strobel HJ. Screening of thermophilic anaerobic bacteria for solid substrate cultivation on lignocellulosic substrates. Biotechnol Progr 2006;22(1):53-9. [16] Shi J, Sharma-Shivappa RR, Chinn M, Howell N. Effect of microbial pretreatment on enzymatic hydrolysis and fermentation of cotton stalks for ethanol production. Biomass Bioenerg 2009;33(1):88-96.

[17] Dharmagadda VS, Nokes SE, Strobel HJ, Flythe MD. Investigation of the metabolic inhibition observed in solid-substrate cultivation of Clostridium thermocellum on cellulose. Bioresour Technol 2010;101(15):6039-44.

[18] Cotta MA, Russell JB. Effect of peptides and amino-acids on efficiency of rumen bacterial protein-synthesis in continuous culture. J Dairy Sci 1982;65(2):226-34.

[19] NREL laboratory analytical procedures

\section{http://www.nrel.gov/biomass/analytical_procedures.html 2012}

[20] Shi J, Chinn MS, Sharma-Shivappa RR. Microbial pretreatment of cotton stalks by solid state cultivation of Phanerochaete chrysosporium. Bioresour Technol 2008;99(14):6556-64. [21] Tien M, Kirk TK. Lignin-degrading enzyme from Phanerochaete chrysosporium purificaiton, characterization, and catalytic properties of a unique $\mathrm{H}_{2} \mathrm{O}_{2}$-requring oxygenase. Proceedings of the National Academy of Sciences of the United States of America-Biological Sciences 1984;81(8):2280-4.

[22] Michel FC, Dass SB, Grulke EA, Reddy CA. Role of manganese peroxidases and lignin peroxidases of Phanerochaete chrysosporium in the decolorization of kraft bleach plant effluent. Appl Environ Microbiol 1991;57(8):2368-75.

[23] Xu FJ, Chen HZ, Li ZH. Solid-state production of lignin peroxidase (LiP) and manganese peroxidase $(\mathrm{MnP})$ by Phanerochaete chrysosporium using steam-exploded straw as substrate. Bioresour Technol 2001;80(2):149-51.

[24] Ride JP. The effect of induced lignification on the resistance of wheat cell-walls to fungal degradation. Physiological Plant Pathology 1980;16(2):187-96. 
[25] Martinez D, Larrondo LF, Putnam N, Gelpke MD, Huang K, Chapman J, et al. Genome sequence of the lignocellulose degrading fungus Phanerochaete chrysosporium strain rp78 Nat Biotechnol 2004;22(7):899-.

[26] Tien M, Kirk TK. Lignin peroxidase of Phanerochaete chrysosporium. Methods Enzymol 1988;161:238-49.

[27] Sannia G, Giardina P, Luna M, Rossi M, Buonocore V. Laccase from Pleurotus ostreatus Biotechnol Lett 1986;8(11):797-800.

[28] Garzillo AMV, Dipaolo S, Burla G, Buonocore V. Differently-induced extracellular phenol oxidases from Pleurotus ostreatus. Phytochemistry 1992;31(11):3685-90.

[29] Asgher M, Asad MJ, Legge RL. Enhanced lignin peroxidase synthesis by Phanerochaete chrysosporium in solid state bioprocessing of a lignocellulosic substrate. World J Microbiol Biotechnol 2006;22(5):449-53.

[30] Couto SR, Moldes D, Liebanas A, Sanroman A. Investigation of several bioreactor configurations for laccase production by Trametes versicolor operating in solid-state conditions. Biochem Eng J 2003;15(1):21-6.

[31] Moldes D, Lorenzo M, Sanroman MA. Different proportions of laccase isoenzymes produced by submerged cultures of Trametes versicolor grown on lignocellulosic wastes. Biotechnol Lett 2004;26(4):327-30.

[32] Gold MH, Alic M. Molecular-biology of the lignin-degrading basidiomycete Phanerochaete chrysosporium. Microbiol Rev 1993;57(3):605-22.

[33] Kapich AN, Prior BA, Botha A, Galkin S, Lundell T, Hatakka A. Effect of lignocellulosecontaining substrates on production of ligninolytic peroxidases in submerged cultures of Phanerochaete chrysosporium ME-446. Enzyme Microb Technol 2004;34(2):187-95. [34] Jager A, Croan S, Kirk TK. Production of ligninases and degradation of lignin in agitated submerged cultures of Phanerochaete chrysosporium. Appl Environ Microbiol 1985;50(5):12748.

[35] Jimenez-Tobon G, Kurzatkowski W, Rozbicka B, Solecka J, Pocsi I, Penninckx MJ. In situ localization of manganese peroxidase production in mycelial pellets of Phanerochaete chrysosporium. Microbiology-Sgm 2003;149:3121-7. [36] Mitchell DA. In: Doelle HW, Mitchell DA, Rolz CE, editors. Solid state cultivation. London and New York: Elsevier Applied Science; 1992, p. 17-28. 
464 [37] Toca-Herrera J, Osma J, Rodriguez Couto S. Potential of solid-state fermentation for laccase 465 production. In: Mendez-Vilas A, editor. Communicating current research on educational topics 466 and trends in applied microbiology, 2007, p. 391-400.

467 [38] Gervais P, Molin P. The role of water in solid-state fermentation. Biochem Eng J $468 \quad 2003 ; 13(2-3): 85-101$.

469 [39] Lonsane BK, Ghildyal NP, Budiatman S, Ramakrishna SV. Engineering aspects of solid470 state fermentation. Enzyme Microb Technol 1985;7(6):258-65.

471 [40] Mitchell D, Berovic M, Krieger N. Biochemical engineering aspects of solid state 472 bioprocessing. Adv Biochem Eng/Biotechnol 2000;68:61-138.

473 [41] Sutherland JB. Regulation of cellulolytic activity in the white-rot fungus Ischnoderma 474 resinosum. Mycologia 1986;78(1):52-5.

475 [42] Kamei I, Hirota Y, Mori T, Hirai H, Meguro S, Kondo R. Direct ethanol production from 476 cellulosic materials by the hypersaline-tolerant white-rot fungus Phlebia sp MG-60. Bioresour 477 Technol 2012;112:137-42.

478 [43] Okamoto K, Nitta Y, Maekawa N, Yanase H. Direct ethanol production from starch, wheat 479 bran and rice straw by the white rot fungus Trametes hirsuta. Enzyme Microb Technol $480 \quad 2011 ; 48(3): 273-7$. 